\title{
Nutrition in the prevention of gastrointestinal cancer.
}

Citation for published version (APA):

van den Brandt, P. A., \& Goldbohm, R. A. (2006). Nutrition in the prevention of gastrointestinal cancer. Best Practice \& Research in Clinical Gastroenterology, 20(3), 589-603.

https://doi.org/10.1016/j.bpg.2006.04.001

Document status and date:

Published: 01/01/2006

DOI:

10.1016/j.bpg.2006.04.001

Document Version:

Publisher's PDF, also known as Version of record

\section{Please check the document version of this publication:}

- A submitted manuscript is the version of the article upon submission and before peer-review. There can be important differences between the submitted version and the official published version of record.

People interested in the research are advised to contact the author for the final version of the publication, or visit the DOI to the publisher's website.

- The final author version and the galley proof are versions of the publication after peer review.

- The final published version features the final layout of the paper including the volume, issue and page numbers.

Link to publication

\footnotetext{
General rights rights.

- You may freely distribute the URL identifying the publication in the public portal. please follow below link for the End User Agreement:

www.umlib.nl/taverne-license

Take down policy

If you believe that this document breaches copyright please contact us at:

repository@maastrichtuniversity.nl

providing details and we will investigate your claim.
}

Copyright and moral rights for the publications made accessible in the public portal are retained by the authors and/or other copyright owners and it is a condition of accessing publications that users recognise and abide by the legal requirements associated with these

- Users may download and print one copy of any publication from the public portal for the purpose of private study or research.

- You may not further distribute the material or use it for any profit-making activity or commercial gain

If the publication is distributed under the terms of Article $25 \mathrm{fa}$ of the Dutch Copyright Act, indicated by the "Taverne" license above, 


\title{
Nutrition in the prevention of gastrointestinal
} cancer

\author{
Piet A. van den Brandt* PhD \\ Professor of Epidemiology \\ Department of Epidemiology, Maastricht University, P.O. Box 616, 6200 MD Maastricht, The Netherlands
}

\section{R. Alexandra Goldbohm' PhD}

Senior Scientist

Department of Food and Chemical Risk Analysis, TNO Quality of Life, P.O. Box 360, 3700 Al Zeist, The Netherlands

Diet has been hypothesized to play a role in the etiology of gastrointestinal cancer for a long time. Initially, strong evidence of such effects was found in retrospective epidemiological studies. Dietary habits, in particular those from the distant past, are difficult to measure, however. Results from recent, prospective and larger studies of better quality did not always confirm these associations. Consumption of fruits and vegetables appear to have a modest role in the prevention of gastrointestinal cancers. In contrast, the roles of alcohol consumption and overweight on risk of gastrointestinal cancer have become much clearer. Overweight and obesity are important risk factors for adenocarcinoma (but not squamous carcinoma) of the esophagus, gastric cardia carcinoma (but not noncardia carcinoma), and colorectal cancer, the latter in particular among men. Alcohol consumption is a risk factor for squamous carcinoma (but not adenocarcinoma) of the esophagus, gastric cancer and colorectal cancer. Selenium may be inversely related to esophageal and gastric cancer.

Key words: esophageal neoplasms; stomach neoplasms; pancreatic neoplasms; colorectal neoplasms; epidemiology; alcohol consumption; body weight; fruit; vegetables.

Information on the role of nutrition in the aetiology of cancer is usually derived from carcinogenicity experiments on animals, in vitro mutagenicity experiments in bacterial and mammalian cell test systems and epidemiological studies among humans. The main disadvantage of in vitro and animal experiments is the problem of extrapolating results to humans. Furthermore, it has been argued that, for example, contrasting theories on

\footnotetext{
* Corresponding author. Tel.: + 3 I 4338823 6I; fax: + 3 I 433884128.

E-mail addresses: pa.vandenbrandt@epid.unimaas.nl (P.A. van den Brandt), bausch@voeding.tno.nl (R.A. Goldbohm).

Tel.: +3I 306944 755; fax: + 31306944070 .
}

I52I-69|8/\$ - see front matter (C) 2006 Elsevier Ltd. All rights reserved. 
fat and colorectal cancer can be proved or disproved depending on the selected animal model.' As studies among humans provide the most realistic evidence on the cancerpreventive potential of nutrition, this chapter will focus on epidemiological findings about diet and cancer.

Among the most important epidemiological study types are the retrospective casecontrol study and the prospective cohort study. In case-control studies on diet and cancer, the investigator attempts to assess dietary habits of cancer cases in the past and compare these with those of a (matched) control group without cancer. In prospective cohort studies usual diet is assessed in a group of healthy subjects (the cohort), after which these subjects are followed up for cancer incidence. Besides randomized controlled trials, cohort studies provide the strongest evidence because of their prospective nature. Nevertheless, due to chance and variability between studies (caused by differences in design, population and methodology), confirmation of results is very important. Therefore, epidemiologists follow a 'weight of evidence' approach, in which information from all good-quality studies is combined. Much value is therefore attached to meta-analyses and pooled analyses of studies.

We will now discuss overall findings from the various epidemiological studies regarding the role of diet in the etiology of esophageal, gastric, pancreatic and colorectal cancer. We will base our discussion as much as possible on published reviews and meta-analyses, and evidence from prospective studies. Case-control studies will only be used when there is no evidence from prospective studies. We also focus on several common dietary risk factors for these tumors, such as fruit and vegetables, alcohol and body weight, while allowing for important site-specific factors as well. We will not discuss gene-nutrient interactions in this chapter, given space limitations and current uncertainties surrounding this.

\section{ESOPHAGEAL CANCER}

Esophageal cancer can be divided in esophageal squamous cell carcinoma (ESCC)mostly occurring in upper parts of the esophagus-which used to represent $90 \%$ of all cases, and adenocarcinoma-mostly located in the lower third of the esophagus - which used to represent $10 \%$ in the past. While the incidence of esophageal adenocarcinoma (EAC) has increased rapidly over the past 3 decades in many western countries, ${ }^{2,3}$ in the US, the incidence of EAC rose six fold from 1975-200I, more than any other major cancer. ${ }^{4}$ At the moment, about $50 \%$ of new cases of esophageal cancer in the western world are of the EAC type, ${ }^{5}$ while ESCC occurs at relatively high frequency in many developing countries. Risk factors for both histological types differ substantially. Some recent epidemiologic studies distinguish the histological types of esophageal cancer, ${ }^{6}$ but in many earlier studies this was not the case, and presumably these studies included mostly ESCC cases. Both types have an extremely poor prognosis.

\section{Alcohol}

Besides smoking, alcohol drinking is an important risk factor-with a clear doseresponse relationship-for esophageal cancer, specifically for the squamous cell type (ESCC). In western countries, about $90 \%$ of ESCC is caused by a combination of alcohol and tobacco smoking. In a recent meta-analysis for esophageal cancer, including 27 casecontrol studies and one cohort study, an increased risk of esophageal cancer was found 


\begin{tabular}{|c|c|c|c|c|}
\hline Category & $\begin{array}{l}\text { ESCC } \\
\text { OR }(95 \% \mathrm{Cl})\end{array}$ & $\begin{array}{l}\text { EAC } \\
\text { OR }(95 \% \mathrm{Cl})\end{array}$ & $\begin{array}{l}\text { GCC } \\
\text { OR }(95 \% \mathrm{Cl})\end{array}$ & $\begin{array}{l}\text { GNCC } \\
\text { OR }(95 \% \mathrm{Cl})\end{array}$ \\
\hline \multicolumn{5}{|c|}{ Body mass index $\left(\mathrm{kg} / \mathrm{m}^{2}\right)$} \\
\hline$<20$ & $1.93(0.90-4.11)$ & $1.44(0.67-3.10)$ & $0.50(0.12-2.10)$ & $1.75(1.00-3.08)$ \\
\hline $20-24$ & I.00 (ref) & 1.00 (ref) & 1.00 (ref) & 1.00 (ref) \\
\hline $25-29$ & $1.13(0.7 \mathrm{I}-1.80)$ & $1.68(1.18-2.40)$ & $1.37(0.89-2.10)$ & I.II (0.80-1.54) \\
\hline$\geq 30$ & $0.28(0.10-0.79)$ & $1.93(1.24-3.01)$ & $1.46(0.84-2.54)$ & $0.87(0.54-\mathrm{I} .4 \mathrm{I})$ \\
\hline $\mathrm{p}$-trend & $p=0.01$ & $p=0.005$ & $p=0.04$ & $p=0.18$ \\
\hline \multicolumn{5}{|l|}{ Alcohol (units/day) $)^{\mathrm{a}}$} \\
\hline $0-2$ & I.00 (ref) & 1.00 (ref) & 1.00 (ref) & 1.00 (ref) \\
\hline $3-15$ & I.0I (0.59-I.72) & $1.06(0.76-1.49)$ & $1.08(0.70-1.69)$ & $0.99(0.72-1.36)$ \\
\hline 16-34 & $2.44(I .26-4.7 \mid)$ & $0.69(0.39-1.20)$ & $1.22(0.67-2.24)$ & $0.91(0.55-\mid .5 I)$ \\
\hline \multicolumn{5}{|l|}{ Smoking status } \\
\hline Nonsmoker & 1.00 (ref) & 1.00 (ref) & 1.00 (ref) & 1.00 (ref) \\
\hline Ex-smoker & $0.61(0.26-1.43)$ & $1.07(0.70-1.64)$ & $1.40(0.85-2.30)$ & $1.10(0.7 \mid-1.70)$ \\
\hline Current smoker & $1.64(1.05-2.56)$ & $1.45(1.06-1.99)$ & $1.38(0.92-2.09)$ & $1.70(1.26-2.29)$ \\
\hline
\end{tabular}

beginning at two alcoholic drinks per day. ${ }^{7}$ A Japanese cohort study, not included in the meta-analysis, found a relative risk of over two for death due to esophageal cancer for people drinking alcoholic beverages four or more times per week. ${ }^{8}$ This increased risk is not limited to particular types of alcoholic beverages (e.g. calvados), but occurs with any type of alcoholic beverages, suggesting that this increased risk is attributable to alcohol itself (ethanol). Nevertheless, several studies have observed stronger risk increases among consumers of stronger drinks, and therefore an additional risk increase due to specific contaminants cannot be ruled out. Alcohol drinking and tobacco smoking act synergistically in increasing the risk of ESCC. The risk of EAC is not or only weakly related to alcohol drinking ${ }^{9-13}$ (Table I).

\section{Body weight}

In contrast to alcohol drinking, being overweight or obese is associated with an increased risk of EAC and not with ESCC risk. Almost all studies, among them three cohort studies, report a positive association between overweight and EAC risk. ${ }^{14}$ In most case-control studies, increased risks were observed with higher body mass index (BMI, body weight divided by height squared $\left(\mathrm{kg} / \mathrm{m}^{2}\right)$ ), notably with obesity. ${ }^{11,15}$ In the US Cancer Prevention Study ${ }^{16}$, BMI was positively associated with esophageal cancer mortality; no distinction between histological subtypes was made. In a Norwegian cohort study overweight and obesity were associated with increased risks of EAC in both men and women (RRs ranging from 2.1 to 2.6 for BMI of $30+\mathrm{kg} / \mathrm{m}^{2}$ ). Opposite associations were found with risk of ESCC in men and women. ${ }^{17}$ Comparable results were reported from England ${ }^{13}$ (Table I).

An increased incidence of gastric reflux due to abdominal pressure has been proposed as the underlying (intermediate) cause of the elevated risk of adenocarcinoma in persons with high BMI. ${ }^{18}$ However, the association between $\mathrm{BMI}$ and risk of EAC was also observed for subjects without gastro-esophageal reflux symptoms ${ }^{11,13}$; this 
suggests that other mechanisms than reflux may (also) be behind the elevated risk for those with high BMI. Still few prospective data are available on this issue.

\section{Fruits and vegetables}

More than 30 case-control studies, often hospital-based, have been published on fruit intake and esophageal cancer. A recent IARC report ${ }^{19}$ concluded from the case-control studies that the mean OR was $0.54(95 \% \mathrm{Cl} 0.48-0.61)$, range $0.14-1.50$, comparing subjects in high intake categories with subjects in low intake categories. Only three cohort studies have been reported, two from China and one from Japan. A borderline significant inverse association was found with total fruit intake in Japan ${ }^{20}$. No associations were found in the Chinese studies, however. ${ }^{21,22}$ Regarding vegetables, IARC arrived for the case-control studies at a mean $\mathrm{OR}=0.64(95 \% \mathrm{Cl} 0.57-0.72)$, range $0.10-0.97 .{ }^{19}$ Four cohort studies were conducted in China or Japan. The Japanese studies found no association, ${ }^{20,23}$ whereas the Chinese studies reported (borderline) significant inverse associations with vegetables. ${ }^{21,22}$ Few case-control and no cohort studies have been reported on EAC specifically; the IARC report did not indicate clear differences in associations between EAC and ESCC, however.

\section{Vitamins and minerals}

High intake of antioxidants, such as vitamins $C$ and $E$, selenium and beta-carotene, may have a protective effect on the risk of certain upper Gl malignancies. Case-control studies analysing for beta-carotene, vitamins $B_{2}, C$ and $E$ intakes have tended to find inverse associations between intakes of these nutrients and risk of esophageal cancer. $A$ large randomized intervention trial of vitamin and mineral supplementation was conducted in Linxian, China, known for its high rates of esophageal and gastric cancer and a low intake of several micronutrients. Overall mortality decreased in those receiving supplementation with beta-carotene, vitamin $\mathrm{E}$, and selenium, mainly due to lower stomach cancer rates (relative risk, $0.79 ; 95 \% \mathrm{Cl}, 0.64-0.99) .{ }^{24}$ In a follow-up study from the Linxian trial, subjects with esophageal dysplasia who were receiving multivitamin and multimineral supplementation had regression of the dysplasia. ${ }^{25}$ The effects of separate vitamins and minerals could not be teased out, however. In a randomized controlled trial from the US, a nonsignificant reduction in mortality from esophageal cancer $(R R=0.33 ; 95 \% \mathrm{Cl}, 0.03-1.84)$, was observed in subjects receiving selenium. ${ }^{26}$ Also from the Linxian trial, pretrial serum selenium levels were inversely associated with the incidence of esophageal and gastric cardia tumors. ${ }^{27,28}$ In a prospective cohort study conducted in Finland, a low selenium region prior to fertilization of the soil with selenium, a lower risk of esophageal and stomach cancer in individuals with relatively high baseline serum selenium levels was observed. ${ }^{29}$

\section{GASTRIC CANCER}

It is important to discern between adenocarcinoma of the proximal stomach (cardia, GCC) and adenocarcinoma arising in other parts of the stomach (body, GNCC). The prognosis of proximal cancers may be even worse than those of distal cancers. ${ }^{30}$ While the incidence of gastric noncardia cancer has sharply declined in the past decades, the incidence of gastric cardia cancer (GCC) has increased quite rapidly over the past 
three decades in many western countries, together with EAC. ${ }^{2}$ The commonly occurring infection with $\mathrm{H}$. Pylori, which also causes gastric ulcers, increases the risk of gastric cancer two-to-threefold. ${ }^{31}$ Earlier, it was estimated that $35-60 \%$ of gastric cancers can be attributed to $\mathrm{H}$. Pylori infection. ${ }^{32-34}$ However, in a recent combined analysis of 12 prospective cohort studies, it was concluded that $\mathrm{H}$. Pylori infection does not increase the risk of GCC, but the risk of GNCC is 5.9 times elevated for those infected with $\mathrm{H}$. Pylori. ${ }^{35}$ Thus, $\mathrm{H}$. Pylori infection is only an established risk factor for GNCC and is estimated to be responsible for about 10\% of the GNCC risk in the American population, according to a very large case-control study. ${ }^{36} \mathrm{GCC}$ may have different aetiological factors than GNCC.

\section{Alcohol}

In a recent meta-analysis, based on 14 case-control studies and two cohort studies, a positive association was found between drinking alcoholic beverages and gastric cancer risk. ${ }^{7}$ Regarding GCC specifically, the results are mixed.

\section{Body weight}

Although overweight and obesity have traditionally not been linked to gastric cancer risk, recent prospective evidence suggests that the risk of GCC is positively associated with $\mathrm{BMI}^{13}$, Table I. In a British cohort study, BMI was associated with risk of GCC, in a dosedependent manner, but not with risk of GNCC. The association with obesity (BMI>30 kg/ $\left.\mathrm{m}^{2}\right)$ was stronger for EAC $(R R=1.93)$ than for $\mathrm{GCC}(\mathrm{RR}=1.46)$; both associations seemed independent of gastro-esophageal reflux and were found in men and women. ${ }^{13}$

\section{Fruits and vegetables}

More than 37 case-control studies have been published on gastric cancer and fruit intake. A recent IARC report ${ }^{19}$ concluded from the case-control studies that the mean OR was $0.63(95 \% \mathrm{Cl}, 0.58-0.69)$, range $0.3 \mathrm{I}-\mathrm{I} .39$, comparing subjects from high fruit intake categories with subjects from low intake categories. A total of I I cohort studies have been reported; the mean RR of these studies was $0.85(95 \% \mathrm{Cl}, 0.77-0.95)$, range 0.55-1.92, comparing high to low intakes. Regarding vegetables, IARC arrived for the 20 available case-control studies at a mean OR of $0.66(95 \% \mathrm{Cl}, 0.6 \mathrm{I}-0.7 \mathrm{I})$, range 0.30 I.70. The five cohort studies on vegetables and stomach cancer showed a mean RR of 0.94 (95\% Cl, 0.84-I.06), range 0.70-I.25, comparing high to low intakes. For both fruits and vegetables, the IARC analyses showed significant heterogeneity between the ORs from case-control studies, but not from cohort studies. ${ }^{19}$ Two case-control and two cohort studies have reported on GCC specifically; no differences in the associations between GCC and GNCC. Prospective studies have shown weaker inverse associations than case-control studies, and evidence is available that the apparent inverse association seen in case-control studies might be due to recall bias because of lower intake following prediagnostic symptoms. ${ }^{37}$

\section{Vitamins and minerals}

Possible protective micronutrients from fruits and vegetables include vitamin C, vitamin $\mathrm{E}$, beta-carotene and other carotenoids and selenium. Regarding vitamin C, case- 
control studies show an approximate halving of risk associated with high compared to low intake. There were no inverse associations with other vitamins/carotenoids. The few other cohort studies on this issue show mixed results. Two randomized nutrition intervention trials on the effects of vitamin/mineral supplementation on the occurrence of gastric carcinoma showed conflicting results. A trial in Linxian, China, showed that supplements containing $\beta$-carotene, vitamin $E$, and selenium reduced the incidence of gastric carcinoma with $16 \%$ and the mortality with $21 \%$ after 5.25 -year intervention, ${ }^{24}$ whereas, in the ATBC trial in Finland, more cases of gastric carcinoma were diagnosed among those who received $\beta$-carotene or $\alpha$-tocopherol compared with those who did not. ${ }^{38}$ In the Linxian Trial, it is not clear whether a specific component or combination of components of the supplement were responsible for the reduced risk. For gastric cancer, suggestive, but inconsistent, evidence was found for an inverse relationship with toenail selenium ( $R R=0.6$ for highest vs. lowest selenium category) in the NLCS. ${ }^{39}$

A chemoprevention trial of gastric dysplasia in which $2 \mathrm{~g}$ vitamin $\mathrm{C}$ or $30 \mathrm{mg}$ $\beta$-carotene supplements (as antioxidants) and anti-H. Pylori therapy were tested singly or in combination for 6 years in Colombia demonstrated that all three treatments were successful regarding lesion regression rates, with no additional benefit from combining treatments. ${ }^{40}$ However, $\mathrm{H}$. Pylori treatment seemed to be only effective when given singly; some indication of adverse effects was seen when it was administered together with $\beta$-carotene or vitamin $C$. The effects of the treatments on lesion progression were less clear.

\section{Salt}

Most case-control studies have shown a positive association between intake of salt or salted food and gastric cancer. The few cohort studies that reported results on salt or salted food and stomach cancer risk found no clear associations. ${ }^{41}$ In one recent Japanese cohort study no significant association with intake of pickled foods and traditional soups and gastric cancer risk was found ${ }^{42}$ while in another cohort study a significant positive association between salt intake and risk of gastric cancer was seen in men, but not in women. ${ }^{43}$ In the NLCS, the results suggested that intake of dietary salt and several types of cured meat were weakly positively associated with gastric cancer risk. ${ }^{44}$ Thus, the link between salt and gastric cancer is not consistently observed. It is possible that the increased risks could be attributed to other compounds of the foods (possible carcinogens) developed during the preservation process, and not to salt content of the foods. ${ }^{45}$ As in the NLCS, use of table salt was not associated with stomach cancer risk in the only other cohort study that reported on this association. ${ }^{46}$ Also, gastric cancer rates in the USA are low, even though salt intake is not.

\section{Nitrate, nitrite, nitrosamines}

Nitrate can be converted into nitrite and in a nitrosation reaction to $N$-nitroso compounds (e.g. nitrosamines); these are carcinogenic in animal experiments. However, the extrapolation of these results - often obtained with high intakes - to humans and human intake levels is uncertain. In case-control and cohort studies, little evidence has been found regarding nitrate or nitrite intake from food or drinking water and gastric cancer risk (e.g. $\left.{ }^{4,48}\right)$. It seems fair to conclude that nitrate does not increase gastric cancer risk, and it is not advisable to reduce vegetable intake because of nitrate, given the possible beneficial effects of high vegetable intake on gastric cancer 
risk. There are very few epidemiological studies on dietary nitrosamines and stomach cancer. Nitrosamines occurred in the past in smoked and salted fish, cured meats and beer, and appeared to increase the risk of gastric cancer in a French study, ${ }^{47}$ but not in a Finnish study. ${ }^{49}$ Due to other methods of food preservation (e.g. refrigeration, addition of vitamin $C$ and $E$ to cured meats, which block the nitrosation reaction) levels of nitrosamines in foods have substantially decreased.

\section{PANCREATIC CANCER}

Pancreatic cancer is a relatively rare but highly fatal cancer, with 5-year survival rates of less than $5 \%$. Regarding its etiology, still very few risk factors are known, also in the area of nutrition.

\section{Alcohol}

Ten prospective studies have evaluated the association between alcohol and pancreatic cancer risk. While four studies found an increased risk for alcohol drinkers, findings were not always significant and one study made no adjustment for smoking, which is one of the few established risk factors. The other six studies reported no significant associations with alcohol intake. Because of possible residual confounding by smoking, and given the overall results, it seems that alcohol is not an important risk factor for pancreatic cancer.

\section{Body weight}

Overweight and obesity possibly increase the risk of pancreatic cancer. In recent years, various cohort studies have shown elevated risks among overweight and obese subjects, but this is not consistently observed. A meta-analysis of 14 case-control and cohort studies on obesity and pancreatic cancer yielded an OR of $1.02(95 \% \mathrm{Cl}, \mathrm{I} .0 \mathrm{I}-$ I.03) per unit increase in BMI, or equivalently, an OR of I.19 $(95 \% \mathrm{Cl}, \mathrm{I} .10-1.29)$ for a BMI of 30 versus $22 \mathrm{~kg} / \mathrm{m}^{2} .{ }^{50}$ The association was seen in men and women, and in casecontrol and cohort studies, but the analysis was heavily influenced by the results of the large ACS Cancer Prevention Study. ${ }^{16}$ It suggests that pancreatic cancer risk is weakly associated with obesity, but confounding cannot be excluded.

\section{Diabetes mellitus}

Type II diabetes is associated with increased pancreatic cancer risk in many studies. There was doubt about the causal nature of this relationship because pancreatic tumors may also lead to diabetes. In a meta-analysis of 20 studies with data on the duration of diabetes prior to pancreatic cancer, subjects who had diabetes for 5 or more years had a twofold increased risk $(95 \% \mathrm{Cl}, \mathrm{I} .2-3.2)$ of pancreatic cancer compared to individuals without diabetes, or diabetes for less than 5 years. ${ }^{51}$ Using additional data from other studies, it has been concluded that diabetes, that develops 10 or more years prior to cancer diagnosis, is causally related to pancreatic cancer.

The associations between body weight and diabetes suggest that insulin resistance may play a role in pancreatic carcinogenesis. ${ }^{52}$ Following this reasoning, some evidence has been found that impaired glucose metabolism may play a role, and that a diet high in 
glycemic load may increase pancreatic cancer risk in women who already have an underlying degree of insulin resistance. ${ }^{52}$

\section{Fruits and vegetables}

Regarding fruit consumption, a recent IARC review ${ }^{19}$ concluded that, when comparing high versus low intake, the mean OR for 6 case-control studies was 0.72 (95\% Cl, $0.63-$ 0.83 ), range $0.07-0.92$. Nonsignificant inverse associations were also found in three cohort studies. For vegetables, the mean OR in 5 case-control studies was 0.80 $(95 \% \mathrm{Cl}, 0.69-0.93)$, range $0.32-1.03$. In two cohort studies, nonsignificant inverse associations were found. Case-control studies on pancreatic cancer are difficult to interpret because of selection bias due to low response rates among cases and controls, and interviewing of next-of-kins for deceased cases. This might explain why inverse associations from case-control studies are not replicated in cohort studies.

\section{Other dietary factors}

IARC has concluded in 1991 that there is little evidence for a positive association between coffee and pancreatic cancer. ${ }^{53}$ The majority of the 13 cohort studies published since then are consistent with this conclusion. Other possible dietary risk factors include (processed) meat and fat consumption, ${ }^{54}$ carbohydrate and sugar intake, and sugar-sweeted soft drinks. ${ }^{55}$ Too few cohort studies are available to draw conclusions, however.

\section{COLORECTAL CANCER}

Colorectal cancer is usually divided in colon and rectal cancer. The incidence of colon cancer has been increasing in developed countries including Japan, whereas rectal cancer has decreased in Europe ${ }^{56}$ and remained constant in Japan. ${ }^{57}$ The differing time trends provide evidence that the etiology of both cancer sites is not the same.

Besides colorectal cancer, colorectal adenoma are sometimes studied as a early endpoint or predictor of colorectal cancer, as adenoma are likely to be in the pathway of development of malignant tumors through a series of genetic alterations. ${ }^{58}$

\section{Alcohol}

Meta-analyses have shown that alcohol consumption is a risk factor for colon and rectal cancer, in men and women, but quantification of the increase in risk was difficult. ${ }^{59,60} \mathrm{~A}$ recent pooled data analysis, including half a million men and women from eight cohort studies in five countries, found that the risk was increased starting from an alcohol consumption of $30 \mathrm{~g}\left(\sim 3\right.$ drinks) per day. ${ }^{61}$ Compared to nondrinkers, risk increased with $16 \%$ for those drinking $30-45 \mathrm{~g}$ alcohol and with $42 \%$ for those drinking more than $45 \mathrm{~g}$ per day. The type of alcoholic beverage did not seem important, alcohol itself appeared to be the most important factor. All eight studies included in the pooled analysis were consistent for men and women and for colon and rectal cancer. 


\section{Body weight and physical activity}

Cohort studies have demonstrated that overweight and obesity increase the risk of colon cancer, more clearly in men than women. ${ }^{62}$ Recent, very large cohort studies in many parts of the world have confirmed that the risk increases with, for example, $4 \%$ for each unit increase in BMI in Norwegian men ${ }^{63}$ and 2.5-fold for obese Austrian men with a BMI $>=35 .{ }^{64}$ Most of these studies observed no or an only weakly increased risk of colon cancer for overweight and obese women. The association between BMI and rectal cancer is much less pronounced. One study found that waist circumference is a better predictor of colon cancer risk than BMI and showed that risk increases linearly with increasing waist size. ${ }^{65}$ This association was more pronounced in sedentary people.

Physical activity was one of the first factors identified that seemed to consistently protect against colon cancer in men and women. The evidence based on case-control studies is convincing. Cohort studies, however, tended to find less consistent results. This may be due to a lower quality of the physical activity assessment in the cohort studies. Risk of rectal cancer does not appear to be influenced by physical activity.

It is noteworthy that colorectal cancer and type 2 diabetes seem to share many risk factors. Plasma c-peptide (an indicator of insulin production) appeared to be a strong predictor of colorectal cancer in the Physicians' Health Study, independently of BMI. ${ }^{66}$

\section{Fruits and vegetables}

Until recently, it was generally assumed-based on case-control studies and a few small cohort studies - that consumption of a lot of fruits and vegetables would protect against colorectal cancer. Several large cohort studies published since did not consistently confirm this association, however; ${ }^{67-69}$ only a few studies, conducted in Sweden, ${ }^{70}$ the Netherlands ${ }^{71}$ and the United States, ${ }^{72}$ found that high consumption of fruits or fruits and vegetables together showed a decreased risk of colorectal cancer. For the cohort studies, IARC estimated a summary RR of I.00 $(95 \% \mathrm{Cl}, 0.96-\mathrm{I} .05)$ for fruit and 0.97 (0.87-I.08) for vegetable intake. ${ }^{19}$ Altogether, consumption of fruits and vegetables may have a small role, if any, in the prevention of colorectal cancer.

\section{Dietary fibre}

Dietary fibre is a summary term for several types of complex (mainly) carbohydrates that are not digested in the gastrointestinal tract. In a mixed diet, $70-80 \%$ of the fibre is fermented and degraded by the intestinal flora. For practical purposes, fibre is divided according to source: vegetable, fruit and cereal fibre or according to physical properties, i.e. soluble and insoluble. Vegetable and fruit fibre is mainly soluble, whereas cereal fibre is mainly insoluble.

One of the oldest hypotheses in the aetiology of colorectal cancer is the fibre hypothesis. It is based on observations that colorectal cancer is uncommon in developing countries with a high fibre intake and its biological plausibility. Bulking and intestinal transit are both increased with a high fibre diet and could lead to a decreased exposure of the mucosa to carcinogens present in the lumen.

Case-control studies generally observed a decreasing risk with increasing fibre intake. $^{73,74}$ This was seen for colon and rectal cancer and for men and women. A number of recent, large cohort studies did not observe a protective effect of dietary 
fibre, even when they took repeated measurements of fibre intake during the follow-up period into account. ${ }^{75}$ The EPIC study, a European prospective multi-centre cohort study, based on 1000 cases, showed, however, that dietary fibre intake decreased the risk of colorectal cancer with about $25 \%$ in the highest intake quintile (i.e. $>34 \mathrm{~g}$ per day) compared with the lowest quintile ( $<13 \mathrm{~g}$ per day). The association was seen in both sexes, was stronger for colon than for rectal cancer and strongest for cereal and fruit fibre. ${ }^{76}$ Further analysis including 1700 cases confirmed these results and showed that the association was most pronounced for tumors in the distal colon. ${ }^{77}$ Most other available cohort studies contributed to a pooled data analysis including 8000 cases of colorectal cancer. ${ }^{78}$ This analysis found no association between dietary fibre intake and colorectal, colon or rectal cancer. It is not known why these results differ across the two studies, although some explanations have been put forward. ${ }^{79}$ Intake of the same amount of fibre may represent a different fibre composition across studies. Measurement error may play a role, but some of the same studies that did not observe an association with colorectal cancer, did observe one with heart disease. ${ }^{80}$

The effect of fibre supplementation on adenoma recurrence was also studied in two chemoprevention trials among subjects who had at least one adenoma removed, each lasting 3 years. One study treated the treatment group with a cereal fibre supplement ${ }^{81}$ and the other study prescribed a diet high in fibre, vegetables and fruits and low in fat. ${ }^{82}$ Neither study observed an effect of fibre intake on adenoma recurrence.

\section{Meat and fat}

In the nineties, two American cohort studies observed increased risks of colon cancer with consumption of meat, in particular red meat (beef, pork and lamb). ${ }^{83,84}$ Since, then much research has been done to confirm these results. Several reviews and metaanalyses have summarised their findings. ${ }^{85-87}$ A few studies confirmed the positive association, but many other studies did not. The comparison was complicated due to differences in meat variables between the studies. For example, in some studies red meat comprised processed meat, in others it did not.

A positive association between consumption of processed meat (i.e. sausages and other cured meats) and colon cancer appeared to be much more consistent; a metaanalysis calculated that an increase in consumption of $25 \mathrm{~g}$ processed meat per day increased risk with $50 \% .{ }^{86}$ It is speculated that the consistently increased risk may be due to the former presence of nitrosamines in cured meat.

Recent large cohort studies, including a reanalysis of the two mentioned before, show a weak association between fresh (red) meat consumption and colorectal cancer. ${ }^{88-91}$ Again, the comparison is complicated as in some of these studies (red) meat consumption included processed meat. With exception of one of these studies, ${ }^{90}$ all observed an increased risk of colorectal cancer with consumption of processed meat. Studies comparing vegetarians with nonvegetarians demonstrated no difference in colorectal cancer risk between the two groups. ${ }^{92-94}$

It is also hypothesised that the differences in results are attributable to preparation methods of meat: meat fried at high temperature and with a dark surface contains more mutagenic heterocyclic amines (HCAs) than meat prepared differently. Again, this association with HCAs was confirmed in some studies, but not in others. Barbecuing and grilling introduce polycyclic aromatic hydrocarbons (PAHs) into the meat; this may also contribute to the increase in risk ${ }^{95}$, but more research has to be done. It may be that people with a rapid acetylator (NAT2) genotype are more susceptible to these carcinogens in 
meat. ${ }^{96}$ Last but not least, it may be that heme, present in (red) meat in varying amounts, increases the risk for colorectal cancer, but the evidence is not yet conclusive. ${ }^{97}$

Intake of fat has not found to increase risk of colorectal cancer.

\section{Dairy and calcium}

Consumption of dairy products, in particular milk, yoghurt, and buttermilk, is associated with a small decrease in risk of colorectal cancer, as was shown by a pooled analysis of 10 cohort studies including 5000 cases. Consumption of half a litre of milk contributed to $11 \%$ decrease in risk. ${ }^{98}$ A similar association was observed for calcium in this study. It has been proposed that calcium may decrease risk due to its capacity to saponify fatty and cholic acids in the lumen. The association was confirmed in an intervention trial among subjects in whom a colorectal adenoma had been removed. After a 4-year treatment with $1200 \mathrm{mg}$ calcium, adenoma recurrence was $19 \%$ lower than in the placebo group. ${ }^{99}$

\section{Practice points}

- ample consumption of fruits and vegetables may modestly decrease risk of most gastrointestinal cancers

- alcohol intake is a risk factor for colorectal cancer and ESCC, but is not or only weakly associated with EAC, gastric cancer and pancreatic cancer

- risk factors for ESCC (smoking and alcohol) differ strongly from those for EAC (high bodyweight). The dramatic increase in incidence of EAC may largely be due to increase of obesity

- overweight and obesity are also risk factors for colorectal cancer (particularly in men), gastric cardia cancer and possibly pancreatic cancer

- there is suggestive evidence that low selenium intake increases risk of esophageal and gastric cancer

- the role of dietary fibre and (red) meat in colorectal cancer is still controversial

- all things considered, a diet including fruits, vegetables and other plant foods, modest amounts of meat and alcohol and aiming at avoiding overweight, has the best chance of a modest reduction of the risk of gastrointestinal cancer

\section{Research agenda}

- study the role of nutrition in subsites and histological subgroups of $\mathrm{Gl}$ cancers

- further study into the role of (red and processed) meat and fibre in CRC is needed

- prospective studies on upper Gl cancers are highly needed

- development of valid, applicable biomarkers of early disease is highly needed, to enable further RCTs

- detailed studies on interaction between genetic susceptibility and dietary factors in Gl cancers

- investigate the role of diet in subgroups of cancer defined by somatic mutations in tumor suppressor or oncogenes 


\section{REFERENCES}

I. Hill MJ. Experimental studies on fat, fibre and calories in carcinogenesis. In Miller AB (ed.) Diet and the Aetiology of Cancers (Monograph Series of the European School of Oncology). Berlin: Springer, 1989.

2. Devesa SS, Blot WJ \& Fraumeni Jr. JF. Changing patterns in the incidence of esophageal and gastric carcinoma in the United States. Cancer 1998; 83(10): 2049-2053.

3. Botterweck AA, Schouten LJ, Volovics A et al. Trends in incidence of adenocarcinoma of the oesophagus and gastric cardia in ten European countries. Int J Epidemiol 2000; 29(4): 645-654.

4. Pohl H \& Welch HG. The role of overdiagnosis and reclassification in the marked increase of esophageal adenocarcinoma incidence. J Natl Cancer Inst 2005; 97(2): 142-146.

5. Blot WJ, Devesa SS, Kneller RW \& Fraumeni Jr. JF. Rising incidence of adenocarcinoma of the esophagus and gastric cardia. JAMA I99|; 265(I0): |287-I289.

6. Terry $\mathrm{P}$, Lagergren J, Hansen $\mathrm{H}$ et al. Fruit and vegetable consumption in the prevention of oesophageal and cardia cancers. Eur J Cancer Prev 200I; 10(4): 365-369.

7. Bagnardi V, Blangiardo M, La Vecchia C \& Corrao G. Alcohol consumption and the risk of cancer: a metaanalysis. Alcohol Res Health 200I; 25(4): 263-270.

8. Kinjo Y, Cui Y, Akiba S et al. Mortality risks of oesophageal cancer associated with hot tea, alcohol, tobacco and diet in Japan. J Epidemiol 1998; 8(4): 235-243.

9. Kabat GC, Ng SK \& Wynder EL. Tobacco, alcohol intake, and diet in relation to adenocarcinoma of the esophagus and gastric cardia. Cancer Causes Control 1993; 4(2): I23-132.

10. Gammon MD, Schoenberg JB, Ahsan $\mathrm{H}$ et al. Tobacco, alcohol, and socioeconomic status and adenocarcinomas of the esophagus and gastric cardia. J Natl Cancer Inst 1997; 89(17): 1277-1284.

II. Lagergren J, Bergstrom R \& Nyren O. Association between body mass and adenocarcinoma of the esophagus and gastric cardia. Ann Intern Med 1999; 130(II): 883-890.

12. Lagergren J, Bergstrom R, Lindgren A \& Nyren O. The role of tobacco, snuff and alcohol use in the aetiology of cancer of the oesophagus and gastric cardia. Int J Cancer 2000; 85(3): 340-346.

13*. Lindblad M, Rodriguez LA \& Lagergren J. Body mass, tobacco and alcohol and risk of esophageal, gastric cardia, and gastric non-cardia adenocarcinoma among men and women in a nested case-control study. Cancer Causes Control 2005; 16(3): 285-294.

14. Maric RN \& Cheng KK. Overweight and adenocarcinoma of the oesophagus. BMJ 200I; 322(7282): 366.

15. Brown LM, Swanson CA, Gridley $G$ et al. Adenocarcinoma of the esophagus: role of obesity and diet. J Natl Cancer Inst 1995; 87(2): 104-109.

16. Calle EE, Rodriguez C, Walker-Thurmond K \& Thun MJ. Overweight, obesity, and mortality from cancer in a prospectively studied cohort of US adults. N Engl J Med 2003; 348(I7): 1625-1638.

17. Engeland A, Tretli $S$ \& Bjorge T. Height and body mass index in relation to esophageal cancer; 23-year follow-up of two million Norwegian men and women. Cancer Causes Control 2004; 15(8): 837-843.

18. Hagen J, Deitel M, Khanna RK \& Ilves R. Gastroesophageal reflux in the massively obese. Int Surg 1987; 72(I): I-3.

*19. IARC, Fruit and vegetables. IARC Handbooks of Cancer Prevention, Vol. 8. Lyon: IARC Press; 2003.

20. Sauvaget $C$, Nagano J, Hayashi $M$ et al. Vegetables and fruit intake and cancer mortality in the Hiroshima/Nagasaki Life Span Study. Br J Cancer 2003; 88(5): 689-694.

21. Yu Y, Taylor PR, Li JY et al. Retrospective cohort study of risk-factors for esophageal cancer in Linxian, People's Republic of China. Cancer Causes Control 1993; 4(3): 195-202.

22. Guo W, Blot WJ, Li JY et al. A nested case-control study of oesophageal and stomach cancers in the Linxian nutrition intervention trial. Int J Epidemiol 1994; 23(3): 444-450.

23. Hirayama T. A large scale cohort study on the effect of life styles on the risk of cancer by each site. Gan No Rinsho 1990; Spec No: 233-242.

24. Blot WJ, Li JY, Taylor PR et al. Nutrition intervention trials in Linxian, China: supplementation with specific vitamin/mineral combinations, cancer incidence, and disease-specific mortality in the general population. J Natl Cancer Inst 1993; 85(18): I483-1492.

25. Mark SD, Liu SF, Li JY et al. The effect of vitamin and mineral supplementation on esophageal cytology: results from the Linxian Dysplasia Trial. Int J Cancer 1994; 57(2): 162-166. 
26. Clark LC, Combs Jr. GF, Turnbull BW et al. Effects of selenium supplementation for cancer prevention in patients with carcinoma of the skin. A randomized controlled trial. Nutritional Prevention of Cancer Study Group. JAMA 1996; 276(24): 1957-1963.

27*. Mark SD, Qiao YL, Dawsey SM et al. Prospective study of serum selenium levels and incident esophageal and gastric cancers. J Natl Cancer Inst 2000; 92(2I): I753-I763.

28. Wei WQ, Abnet CC, Qiao Y et al. Prospective study of serum selenium concentrations and esophageal and gastric cardia cancer, heart disease, stroke, and total death. Am J Clin Nutr 2004; 79(I): 80-85.

29. Knekt $P$, Aromaa A, Maatela J et al. Serum micronutrients and risk of cancers of low incidence in Finland. Am J Epidemiol 199I; 134(4): 356-36I.

30. Ohno S, Tomisaki S, Oiwa $\mathrm{H}$ et al. Clinicopathologic characteristics and outcome of adenocarcinoma of the human gastric cardia in comparison with carcinoma of other regions of the stomach. J Am Coll Surg 1995; 180(5): 577-582.

31. Danesh J. Helicobacter pylori infection and gastric cancer: systematic review of the epidemiological studies. Aliment Pharmacol Ther 1999; 13(7): 85I-856.

32. Veldhuyzen van Zanten SJ \& Sherman PM. Helicobacter pylori infection as a cause of gastritis, duodenal ulcer, gastric cancer and nonulcer dyspepsia: a systematic overview. Can Med Assoc J 1994; I 50(2): I77-I85.

33. Forman D, Newell DG, Fullerton F et al. Association between infection with Helicobacter pylori and risk of gastric cancer: evidence from a prospective investigation. BMJ 199|; 302(6788): I302-I305.

34. Parsonnet J, Friedman GD, Vandersteen DP et al. Helicobacter pylori infection and the risk of gastric carcinoma. N Engl J Med I99I; 325(I6): II27-II3I.

35. Helicobacter and Cancer Collaborative Group. Gastric cancer and Helicobacter pylori: a combined analysis of 12 case control studies nested within prospective cohorts. Gut 200 I; 49(3): 347-353.

36*. Engel LS, Chow WH, Vaughan TL et al. Population attributable risks of esophageal and gastric cancers. J Natl Cancer Inst 2003; 95(I8): I404-14I3.

37*. Botterweck AA, van den Brandt PA \& Goldbohm RA. A prospective cohort study on vegetable and fruit consumption and stomach cancer risk in The Netherlands. Am J Epidemiol 1998; 148(9): 842-853.

38. The Alpha-Tocopherol \& Beta Carotene Cancer Prevention Study Group. The effect of vitamin E and beta carotene on the incidence of lung cancer and other cancers in male smokers. N Engl J Med I 994; 330: 1029-1035.

39. van den Brandt PA, Goldbohm RA, van 't Veer P et al. A prospective cohort study on toenail selenium levels and risk of gastrointestinal cancer. J Natl Cancer Inst 1993; 85(3): 224-229.

40. Correa P, Fontham ET, Bravo JC et al. Chemoprevention of gastric dysplasia: randomized trial of antioxidant supplements and anti-helicobacter pylori therapy. J Natl Cancer Inst 2000; 92(23): I88I-I888.

4I. Galanis DJ, Kolonel LN, Lee J \& Nomura A. Intakes of selected foods and beverages and the incidence of gastric cancer among the Japanese residents of Hawaii: a prospective study. Int J Epidemiol 1998; 27(2): 173-180.

42. Ngoan LT, Mizoue T, Fujino Yet al. Dietary factors and stomach cancer mortality. Br J Cancer 2002; 87(I): 37-42.

43. Tsugane S, Sasazuki S, Kobayashi M \& Sasaki S. Salt and salted food intake and subsequent risk of gastric cancer among middle-aged Japanese men and women. Br J Cancer 2004; 90(I): I28-I34.

44. van den Brandt PA, Botterweck AA \& Goldbohm RA. Salt intake, cured meat consumption, refrigerator use and stomach cancer incidence: a prospective cohort study (Netherlands). Cancer Causes Control 2003; I 4(5): 427-438.

45. Ward MH \& Lopez-Carrillo L. Dietary factors and the risk of gastric cancer in Mexico City. Am J Epidemiol 1999; I49(10): 925-932.

46. Nomura A, Grove JS, Stemmermann GN \& Severson RK. A prospective study of stomach cancer and its relation to diet, cigarettes, and alcohol consumption. Cancer Res 1990; 50(3): 627-63I.

47. Pobel D, Riboli E, Cornee J et al. Nitrosamine, nitrate and nitrite in relation to gastric cancer: a casecontrol study in Marseille, France. Eur J Epidemiol 1995; I I (I): 67-73.

48. van Loon AJ, Botterweck AA, Goldbohm RA et al. Intake of nitrate and nitrite and the risk of gastric cancer: a prospective cohort study. Br J Cancer 1998; 78(I): I29-135.

49. Knekt $P$, Jarvinen R, Dich J \& Hakulinen T. Risk of colorectal and other gastro-intestinal cancers after exposure to nitrate, nitrite and N-nitroso compounds: a follow-up study. Int J Cancer 1999; 80(6): 852-856.

50*. Berrington de Gonzalez A, Sweetland S \& Spencer E. A meta-analysis of obesity and the risk of pancreatic cancer. Br J Cancer 2003; 89(3): 519-523. 
5I. Everhart J \& Wright D. Diabetes mellitus as a risk factor for pancreatic cancer. A meta-analysis. JAMA 1995; 273(20): 1605-1609.

52. Michaud DS, Liu S, Giovannucci E et al. Dietary sugar, glycemic load, and pancreatic cancer risk in a prospective study. J Natl Cancer Inst 2002; 94(I7): 1293-1300.

53. IARC. Coffee, Tea, Mate Methylxanthines, and Methylglyoxal. IARC Monograph Evaluations of Carcinogenic Risks in Humans. Lyon: IARC Press; 1991.

54. Nothlings U, Wilkens LR, Murphy SP et al. Meat and fat intake as risk factors for pancreatic cancer: the multiethnic cohort study. J Natl Cancer Inst 2005; 97(19): 1458-1465.

55. Schernhammer ES, Hu FB, Giovannucci E et al. Sugar-sweetened soft drink consumption and risk of pancreatic cancer in two prospective cohorts. Cancer Epidemiol Biomarkers Prev 2005; 14(9): 2098-2105.

56. Thygesen LC, Gronbaek M \& Johansen C. Colorectal cancer in Denmark 1943-1997. Dis Colon Rectum 2004; 47(7): |232-124|.

57. Kojima M, Wakai K, Tamakoshi $\mathrm{K}$ et al. Diet and colorectal cancer mortality: results from the Japan Collaborative Cohort Study. Nutr Cancer 2004; 50(I): 23-32.

58. Fearon ER \& Vogelstein B. A genetic model for colorectal tumorigenesis. Cell 1990; 6I(5): 759-767.

59. Longnecker MP, Orza MJ, Adams ME et al. A meta-analysis of alcoholic beverage consumption in relation to risk of colorectal cancer. Cancer Causes Control 1990; I (I): 59-68.

60. Bagnardi $\mathrm{V}$, Blangiardo M, La Vecchia C \& Corrao G. A meta-analysis of alcohol drinking and cancer risk. $\mathrm{Br}$ J Cancer 200I; 85(II): I700-1705.

6I*. Cho E, Smith-Warner SA, Ritz J et al. Alcohol intake and colorectal cancer: a pooled analysis of 8 cohort studies. Ann Intern Med 2004; 140(8): 603-613.

62. Bergstrom A, Pisani P, Tenet $\mathrm{V}$ et al. Overweight as an avoidable cause of cancer in Europe. Int J Cancer 200I; 9 I(3): 42I-430.

63. Engeland A, Tretli S, Austad G \& Bjorge T. Height and body mass index in relation to colorectal and gallbladder cancer in two million Norwegian men and women. Cancer Causes Control 2005; 16(8): 987-996.

64. Rapp K, Schroeder J, Klenk J et al. Obesity and incidence of cancer: a large cohort study of over 145,000 adults in Austria. Br J Cancer 2005; 93(9): 1062-1067.

65. Moore LL, Bradlee ML, Singer MR et al. BMI and waist circumference as predictors of lifetime colon cancer risk in Framingham Study adults. Int J Obes Relat Metab Disord 2004; 28(4): 559-567.

66. Ma J, Giovannucci E, Pollak $M$ et al. A prospective study of plasma C-peptide and colorectal cancer risk in men. J Natl Cancer Inst 2004; 96(7): 546-553.

67. Flood $\mathrm{A}$, Velie EM, Chaterjee $\mathrm{N}$ et al. Fruit and vegetable intakes and the risk of colorectal cancer in the Breast Cancer Detection Demonstration Project follow-up cohort. Am J Clin Nutr 2002; 75(5): 936-943.

68. Michels KB, Edward G, Joshipura KJ et al. Prospective study of fruit and vegetable consumption and incidence of colon and rectal cancers. J Natl Cancer Inst 2000; 92(21): 1740-1752.

69. Pietinen $\mathrm{P}$, Malila N, Virtanen $\mathrm{M}$ et al. Diet and risk of colorectal cancer in a cohort of Finnish men. Cancer Causes Control 1999; 10(5): 387-396.

70. Terry P, Giovannucci E, Michels KB et al. Fruit, vegetables, dietary fiber, and risk of colorectal cancer. J Natl Cancer Inst 200I; 93(7): 525-533.

7I. Voorrips LE, Goldbohm RA, Verhoeven DT et al. Vegetable and fruit consumption and lung cancer risk in the Netherlands Cohort Study on diet and cancer. Cancer Causes Control 2000; I I (2): I0I-II 5.

72. Lin J, Zhang SM, Cook NR et al. Dietary intakes of fruit, vegetables, and fiber, and risk of colorectal cancer in a prospective cohort of women (United States). Cancer Causes Control 2005; 16(3): 225-233.

73. World Cancer Research Fund. Food, Nutrition and the Prevention of Cancer: a Global Perspective. Washington, DC: World Cancer Research Fund / American Institute for Cancer Research; 1997.

74. Howe GR, Benito E, Castelleto R et al. Dietary intake of fiber and decreased risk of cancers of the colon and rectum: evidence from the combined analysis of 13 case-control studies. J Natl Cancer Inst 1992; 84(24): 1887-1896.

75. Michels KB, Fuchs CS, Giovannucci E et al. Fiber intake and incidence of colorectal cancer among 76,947 women and 47,279 men. Cancer Epidemiol Biomarkers Prev 2005; 14(4): 842-849.

76*. Bingham SA, Day NE, Luben $R$ et al. Dietary fibre in food and protection against colorectal cancer in the European Prospective Investigation into Cancer and Nutrition (EPIC): an observational study. Lancet 2003; 36 I (9368): 1496-1501.

77. Bingham SA, Norat T, Moskal A et al. Is the association with fiber from foods in colorectal cancer confounded by folate intake? Cancer Epidemiol Biomarkers Prev 2005; 14(6): I552-I556. 
78*. Park Y, Hunter DJ, Spiegelman D et al. Dietary fiber intake and risk of colorectal cancer: a pooled analysis of prospective cohort studies. JAMA 2005; 294(22): 2849-2857.

79. Baron JA. Dietary fiber and colorectal cancer: an ongoing saga. JAMA 2005; 294(22): 2904-2906.

80. Pereira MA, O'Reilly E, Augustsson $\mathrm{K}$ et al. Dietary fiber and risk of coronary heart disease: a pooled analysis of cohort studies. Arch Intern Med 2004; 164(4): 370-376.

8I. Alberts DS, Martinez ME, Roe DJ et al. Lack of effect of a high-fiber cereal supplement on the recurrence of colorectal adenomas. Phoenix Colon Cancer Prevention Physicians' Network. N Engl J Med 2000; 342(16): II56-II62.

82. Schatzkin A, Lanza E, Corle D et al. Lack of effect of a low-fat, high-fiber diet on the recurrence of colorectal adenomas. Polyp Prevention Trial Study Group. N Engl J Med 2000; 342(I6): I I49-II55.

83. Willett WC, Stampfer MJ, Colditz GA et al. Relation of meat, fat, and fiber intake to the risk of colon cancer in a prospective study among women. N Engl J Med 1990; 323(24): I664-I672.

84. Giovannucci E, Rimm EB, Stampfer MJ et al. Intake of fat, meat, and fiber in relation to risk of colon cancer in men. Cancer Res 1994; 54(9): 2390-2397.

85. Norat T \& Riboli E. Meat consumption and colorectal cancer: a review of epidemiologic evidence. Nutr Rev 200I; 59(2): 37-47.

86. Sandhu MS, White IR \& McPherson K. Systematic review of the prospective cohort studies on meat consumption and colorectal cancer risk: a meta-analytical approach. Cancer Epidemiol Biomarkers Prev 200I; I0(5): 439-446.

87. Norat T, Lukanova A, Ferrari P \& Riboli E. Meat consumption and colorectal cancer risk: dose-response meta-analysis of epidemiological studies. Int J Cancer 2002; 98(2): 24I-256.

88. Wei EK, Giovannucci E, Wu K et al. Comparison of risk factors for colon and rectal cancer. Int J Cancer 2004; I08(3): 433-442.

89. Chao A, Thun MJ, Connell CJ et al. Meat consumption and risk of colorectal cancer. JAMA 2005; 293(2): 172-182.

90. Larsson SC, Rafter J, Holmberg L et al. Red meat consumption and risk of cancers of the proximal colon, distal colon and rectum: the Swedish Mammography Cohort. Int J Cancer 2005; I I3(5): 829-834.

91*. Norat T, Bingham S, Ferrari P et al. Meat, fish, and colorectal cancer risk: the European Prospective Investigation into cancer and nutrition. J Natl Cancer Inst 2005; 97(12): 906-916.

92. Ullmann D, Phillips RL, Beeson WL et al. Cause-specific mortality among physicians with differing lifestyles. JAMA 199I; 265(18): 2352-2359.

93. Key TJ, Fraser GE, Thorogood $M$ et al. Mortality in vegetarians and non-vegetarians: a collaborative analysis of 8300 deaths among 76,000 men and women in five prospective studies. Public Health Nutr 1998; I(I): 33-4I.

94. Sanjoaquin MA, Appleby PN, Thorogood M et al. Nutrition, lifestyle and colorectal cancer incidence: a prospective investigation of 10998 vegetarians and non-vegetarians in the United Kingdom. Br J Cancer 2004; 90(I): II8-121.

95. Cross AJ \& Sinha R. Meat-related mutagens/carcinogens in the etiology of colorectal cancer. Environ Mol Mutagen 2004; 44(I): 44-55.

96. Chan AT, Tranah GJ, Giovannucci EL et al. Prospective study of N-acetyltransferase-2 genotypes, meat intake, smoking and risk of colorectal cancer. Int J Cancer 2005; I I 5(4): 648-652.

97. Balder HF, de Vogel J, Jansen MCJF et al. Heme and chlorophyll intake and risk of colorectal cancer in the Netherlands Cohort Study. Cancer Epidemiol Biomarkers Prev 2006; 15: 717-725.

98. Cho E, Smith-Warner SA, Spiegelman D et al. Dairy foods, calcium, and colorectal cancer: a pooled analysis of 10 cohort studies. J Natl Cancer Inst 2004; 96(I3): 1015-1022.

99. Baron JA, Beach M, Mandel JS et al. Calcium supplements for the prevention of colorectal adenomas. Calcium Polyp Prevention Study Group. N Engl J Med I999; 340(2): I0I-I07. 